\title{
USING REMOTE SENSING METHOD ANALYSIS CHARACTERISTIC OF BOHAI SEA AND YELLOW SEA MIXED ZONE
}

\author{
Guo Jie ${ }^{1}$, YijunHe$^{2,3}$ \\ ${ }^{1}$ Key Laboratory of Coastal Zone Environmental Processes, CAS; Shandong Provincial Key Laboratory of Coastal Zone \\ Environmental Processes; Yantai Institute of Coastal Zone Research, Chinese Academy of Sciences, Yantai, 264003, P. R. \\ China.(jguo@yic.ac.cn ) \\ 2 School of Marine Sciences, Nanjing University of Information Science and Technology 219 \\ Ningliu Road, Nanjing 210044, P.R. China. (Email: yjhe@nuist.edu.cn) \\ ${ }^{3}$ Institute of Oceanology and Key Laboratory of OceanCirculation and Waves, Chinese Academy of Science, 7 Nanhai \\ Road. Qingdao,Shandong 266071, P.R. China
}

\section{ABSTRACT}

In this paper, we use ASCAT and MODIS data to analyze wind field, the temperature and the chlorophyll concentration distribution in Bohai Sea and Yellow Sea mixed zone and compare characteristics with the first 10 years (Except the wind field, it is only 6 years with ASCAT data). We found that high wind weather is too few in winter of 2013, the northerly winds are dominant, and the sea surface temperatures are also high and low chlorophyll concentration into the mixing zone of Yellow Sea and the Bohai Sea trend. There is $6{ }^{\circ} \mathrm{C}$ to $8^{\circ} \mathrm{C}$ sea water into the Bohai Sea.

\section{INTRODUCTION}

The Bohai Sea is China's inland Sea $\left(37^{\circ} 07^{\prime} \mathrm{N}\right.$ to $41^{\circ} 0^{\prime} \mathrm{N}$ and $117^{\circ} 35^{\prime} \mathrm{E}$ to $121^{\circ} 10^{\prime} \mathrm{E}$, about $7.7 \times$ $10^{4} \mathrm{~km}^{2}$ ) and it surrounds by the Liaodong and Shandong peninsulas. The average depth of the Bohai Sea is 18 meters and is dominated by mud and silt-mud sediments. The Bohai Sea consists of Laizhou Bay, Bohai Bay, Liaodong Bay, and the central basin. The sea is nearly enclosed by shallow waters and has a high, rich-quality fishery, a harbor, petroleum, landscapes, and sea salt resources [1]. However, the Bohai strait is the only channel connects the open seas- Yellow Sea. The Yellow sea is a semi-closed shelf shallow sea, Yellow Sea downfold from the west to Jeju Island to the north to the depth of 70-100 m. In the East China Sea, the northeast, south of Jeju Island, there is a flow along the northwest into the south Yellow Sea; it is referred to the Yellow Sea warm current on oceanography. It was the only foreign water in Yellow Sea and has the characteristics of high temperature and high salt and low dissolved oxygen content [2]. Its' strong and weak change on Yellow Sea and Bohai Sea water exchange, as well as the whole Bohai Sea environmental impact has been the concern of the people. So to study the connected to the Yellow Sea and Bohai Sea zone's the temperature, the chlorophyll concentration distribution and the 
change of wind field in winter have great significance.

\section{DATA AND METHOD}

In this paper, we analysis wind field, sea temperature (SST) and chlorophyll concentration of Yellow Sea and Bohai Sea mixed zone (Fig.1Rectangle ABCD) in 2013 winter and comparison their average values of the first 10 years (Except the wind field, it is only 6 years with ASCAT data). The wind field inversion data are used ASCAT_L3 data (resolution: $25 \mathrm{~km} * 25 \mathrm{~km})$. The sea temperature and chlorophyll concentration inversion are used MODIS_L3 (resolution: $9 \mathrm{~km} * 9 \mathrm{~km}$ ) data. The time is in December 2013 and January, February 2014. Study area(See Fig.1 Rectangle ABCD) is near latitude $37.5^{\circ} \sim 39^{\circ} \mathrm{N}$, longitude $120^{\circ} \sim 124^{\circ} \mathrm{E}$ in the Bohai Sea and Yellow Sea. Research method is the data statistical analysis and to use monthly average data.

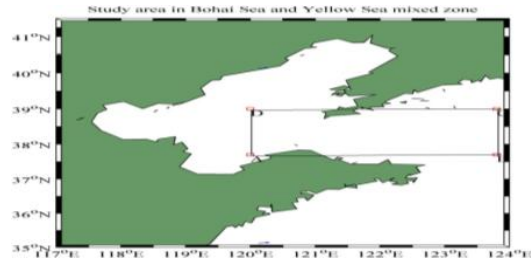

Fig.1 Study area (Rectangle ABCD)

There are 90 data in this area, in the winter of 2013the average wind speed is $7.8317 \mathrm{~m} / \mathrm{s}$ and in 2007-2012 are 7.8229 m/s (Fig.3a) Bohai Sea and Yellow Sea. In Fig.4a wind scale (Beaufort scale) show that $1,2,3,4,5$ and 6 represent the $1 \sim 2,2 \sim 3$, $3 \sim 4,4 \sim 5,5 \sim 6$ and $6 \sim 7$ wind scale, respectively. Rule 10 min average maximum wind speed level above 6 of winds $(\geq 10.8 \mathrm{~m} / \mathrm{s})$ is called high wind and 8 grade $(\geq 17.2 \mathrm{~m} / \mathrm{s})$ for the strong wind [4].
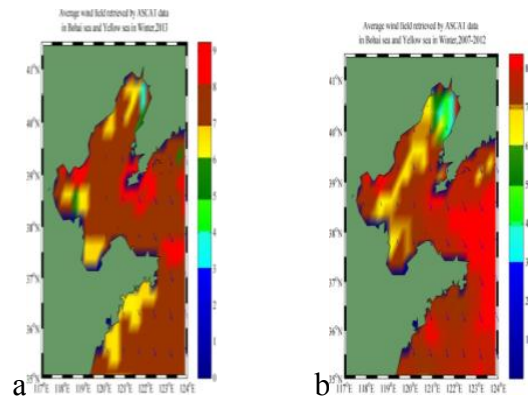

Fig.2 Average wind field retrieved by ASCAT data in Bohai Sea and Yellow Sea in winter, 2013(a) and 2007 2012 (b) (Unit: m/s)
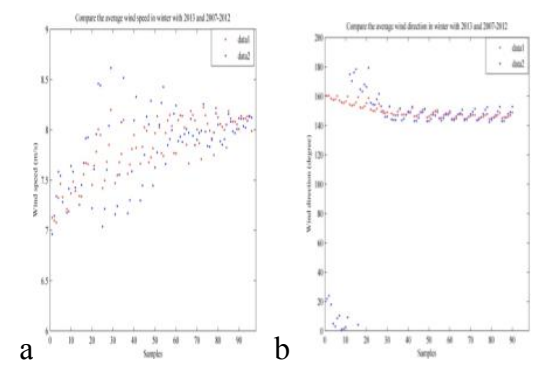

Fig.3 Compare the average wind field in winter of 2013 and 2007-2012 in Bohai Sea and Yellow Sea mixed zone, wind speed (a) and wind direction (b)
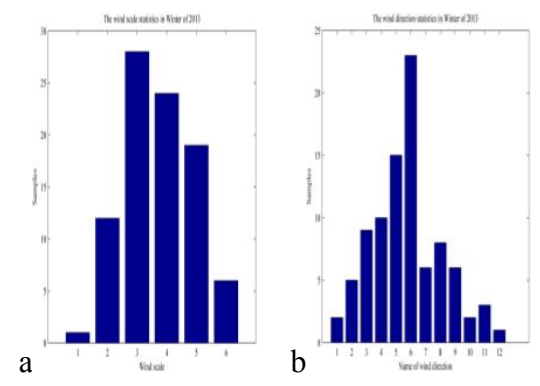

Fig.4 The average wind speed (a) and direction (b) statistics in the winter of 2013 in Bohai Sea and Yellow Sea mixed zone

In winter of 2013, the high wind days appeared 6 times. Average monthly has two days. When it 
compared with the mean monthly of 2011 [4] the high wind 9.5 days a lot less. The $1 \sim 2,2 \sim 3,3 \sim 4$, $4 \sim 5,5 \sim 6$ wind scale days appeared 1 day, 12 days, 28 days, 24 days and 19 days, respectively. In Fig.4b wind direction 12 is divided into. The $1 \sim 12$ represent the East (2 days), South (5 days), West (9 days), North (10 days), North between East(15 days), North between West(23 days), South between West (6 days), South between East ( 8 days), West between North ( 6 days), West between South( 2 days), East between South (3 days) and East between North (1 day). We found that Northerly winds 48 days appeared in winter of 2013. From Figs.2 and 3b,4b(data1-2007-2012, data2-2013) we found that both in the winter of 2013 and 2007-2012 are dominated by northwest wind in Bohai Sea and Yellow Sea mixed zone.

From Fig.5 we can see that both in the winter of 2013 and 2003-2012 are dominated by temperature distribution from $4{ }^{\circ} \mathrm{C}$ to $8{ }^{\circ} \mathrm{C}$ in Bohai Sea and Yellow Sea mixed zone. There are 504 data in this area; in the winter of 2013 the average temperature is $7.2296{ }^{\circ} \mathrm{C}$ and in $2003-2012$ is $6.6976{ }^{\circ} \mathrm{C}$ (Fig.7a, data1-2013, data2-2003 2012).

We can see from Fig. 6 that both in the winter of 2013 and 2003-2012 are dominated by chlorophyll concentration distribution from $0 \mathrm{mg} / \mathrm{m}^{3}$ to $4 \mathrm{mg} / \mathrm{m}^{3}$ in Bohai Sea and Yellow Sea mixed zone. There are 443 data in this area, in the winter of 2013 the average chlorophyll concentration is $2.9865 \mathrm{mg} / \mathrm{m} 3$ and in 2003-2012 is $2.9490 \mathrm{mg} / \mathrm{m} 3$ (Fig.7b, data1:2003 2012 and data2: 2013).

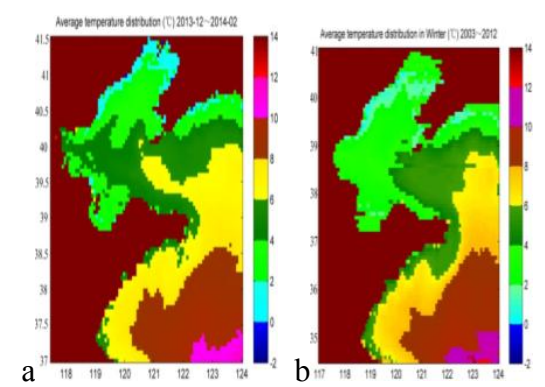

Fig.5 Average temperature distribution in winter, 2013 (a) and 2003 2012 (b)

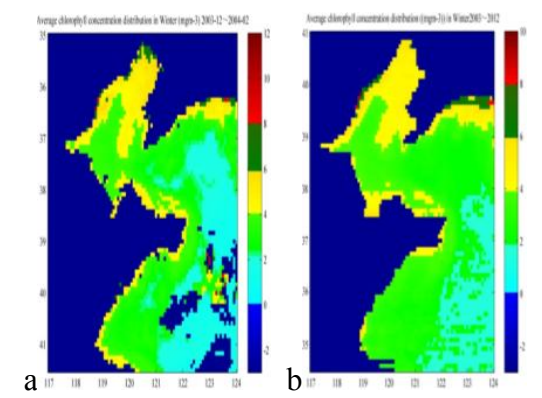

Fig.6 Average chlorophyll concentration distribution in winter, 2013 (a) and 2003 2012(b)
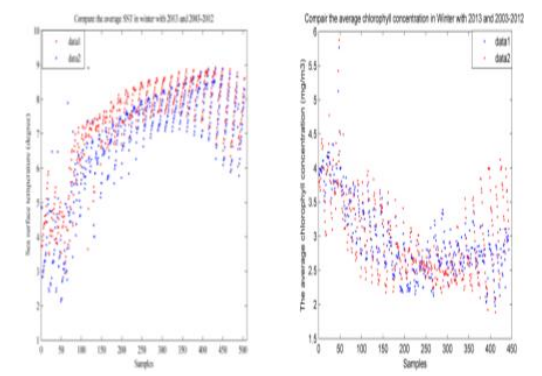

Fig.7 Compare the average SST and chlorophyll concentration distribution in winter of 2013 and 2003 2012 in Bohai Sea and Yellow Sea mixed zone, SST (a) and chlorophyll concentration (b)

\section{DISCUSSION AND CONCLUSIONS}

From data analysis in winter of 2013 (Fig.2, Fig.3b 
and Fig. $4 \mathrm{~b}$ )found that wind direction is in dominate with Northerly winds in mixed zone of Bohai Sea and Yellow Sea and the average wind speed (Fig.3a and Fig.4a) in 2013 is only $0.0088 \mathrm{~m} / \mathrm{s}$ higher than in 2007-2012. It is said that the average wind speed in 2013 and average wind speed from 2003 to 2012 were little changed and high wind weather 2 days are less than the average 9.5days of previous years (2010) [4]. However, the SST (Fig.7) is $0.5319{ }^{\circ} \mathrm{C}$ significantly higher than in $2003 \sim 2012$ and the chlorophyll concentration in mixed zone in winter is $0.0373 \mathrm{mg} / \mathrm{m}^{3}$ higher than in $2003 \sim 2012$. It is little changed. But we can see from the Fig. 6a there is a low average chlorophyll concentration $0-2 \mathrm{mg} / \mathrm{m}^{3}$ close to the Bohai Sea mixing zone compared with the previous decade (Fig.6b).

As the winter winds weaken, less ocean heat, the upward trend in sea surface temperature compared with a normal year easily [5]. But in Fig.5 we speculate whether Yellow Sea warm current into the Bohai Sea. Because mixed zone data abnormal must cause the Bohai Sea ecological environment change or climate change (ENSO) [3]. Therefore, further research work will be added to the zone salinity analysis to confirm speculation that the results.

\section{ACKNOWNLODGYMENT}

This paper is supported by the National Natural Science Foundation of China (No. 41176160). The author express their great thanks to the funding provided to the "Strategic Priority Research Program" of the Chinese Academy of Sciences, Grant No.

XDA01020304

We are grateful to ECMWF, EUMETSAT, KNMI, IFREMER/CERSAT, GODIVA, NOAA, Météo-France, NDBC, O\&SI SAF, PMEL, and UK MetOffice, for providing the Buoy, numerical, and satellite data used in daily ASCAT data production, evaluation, and Validation. MODIS data were provided by NASA.

\section{REFERENCES}

[1] Guo Jie, Liu Xin, Xie Qiang, Characteristics of the Bohai Sea oil spill and its impact on the Bohai Sea ecosystem. Chinese Science Bulletin. Vol.58 No.19: 2276 2281, 2013.

[2] Song Xin, Lin XiaoPei, Wang Yue, The variability of the Yellow Sea warm current axis in Winter and its possible reason. Periodical of Ocean University of China. 39(sup): 259, 2009.

[3] Wang Bin, Thrusts and prospects on understanding and predicting Asian monsoon climate. Acta Meteorologica Sinica, 66 (5): 653 669, 2008.

[4] Li Yan, Chang Hang, Wu Qi Ping, Study of the characteristic and difference betweent sea and land wind of Bohai. Plateau Meteorology. 32(1):298-304, 2013.

[5] Qin ZhengKun, Sun ZhaoBo, Influence of Abnormal East Asian Winter Monsoon on the Northwestern Pacific Sea Temperature. Chinese Journal of Atmospheric Sciences. 30(2): 257-267, 2006. 